\title{
Abdominal Surgical Procedure
}

National Cancer Institute

\section{Source}

National Cancer Institute. Abdominal Surgical Procedure. NCI Thesaurus. Code C16120.

Surgery performed on any part of the abdominal region of the body. 